Article

\title{
Fabrication of Poly(p-Phenylene)/Zeolite Composites and Their Responses Towards Ammonia
}

\section{Pimchanok Phumman, Sumonman Niamlang and Anuvat Sirivat *}

Center of Excellence in Petroleum Petrochemicals and Advanced Materials, The Petroleum and Petrochemical College, Chulalongkorn University, Bangkok, Thailand;

E-Mails: pimnokp@yahoo.com (P.P.); tanggggo@hotmail.com (S.N.)

* Author to whom correspondence should be addressed; E-Mail: anuvat.s@chula.ac.th (A.S.);

Tel.: +66-2218-4131, Fax: +66-2611-7221.

Received: 8 September 2009; in revised form: 23 September 2009 / Accepted: 9 October 2009 / Published: 13 October 2009

\begin{abstract}
Poly( $p$-phenylene) (PPP) was chemically synthesized via oxidative polymerization using benzene and doped with $\mathrm{FeCl}_{3}$. The electrical conductivity response of the doped PPP (dPPP) towards $\mathrm{CO}, \mathrm{H}_{2}$ and $\mathrm{NH}_{3}$ is investigated. dPPP shows no electrical conductivity response towards the first two gases $\left(\mathrm{CO}\right.$ and $\left.\mathrm{H}_{2}\right)$, but it shows a definite negative response towards $\mathrm{NH}_{3}$. The electrical conductivity sensitivity of dPPP increases linearly with increasing $\mathrm{NH}_{3}$ concentration. To improve the sensitivity of the sensor towards $\mathrm{NH}_{3}, \mathrm{ZSM}-5$ zeolite is added into the conductive polymer matrix. The electrical sensitivity of the sensor increases with increasing zeolite content up to $30 \%$. The effect of the type of cation in the zeolite pores is investigated: namely, $\mathrm{Na}^{+}, \mathrm{K}^{+}, \mathrm{NH}_{4}^{+}$and $\mathrm{H}^{+}$. The electrical conductivity sensitivity of the composites with different cations in the zeolite can be arranged in this order: $\mathrm{K}^{+}<$no zeolite $<\mathrm{Na}^{+}<\mathrm{NH}_{4}^{+}<\mathrm{H}^{+}$. The variation in electrical sensitivity with cation type can be described in terms of the acid-base interaction, the zeolite pore size and surface area. The PPP/Zeolite composite with $\mathrm{H}^{+}$possesses the highest electrical sensitivity of -0.36 since $\mathrm{H}^{+}$has the highest acidity, the highest pore volume and surface area, which combine to induce a more favorable $\mathrm{NH}_{3}$ adsorption and interaction with the conductive polymer.
\end{abstract}

Keywords: conductive polymer; gas sensor; poly(p-phenylene); ammonia; ZSM-5 


\section{Introduction}

Conductive polymers (CPs) are well-known as potential materials in several sensing applications such as $\mathrm{pH}$ sensors [1], ion selective sensors [2], humidity sensors [3], biosensors [4], and also gas sensors [5]. There are several studies related to the gas sensing properties of materials such as polyaniline (PANi) [6], poly(thiophene) (PTh) [7] and polypyrrole (PPy) [8]. Poly(p-phenylene) (PPP) is a conductive polymer which possesses several advantages such as the ease of synthesis, high stability, and chemical resistance. PPP can be used in many other applications: rechargeable batteries, electrodes, etc. [9]. PPP has also been used as a gas sensing material since its optical and electrical properties change under exposures to particular gases [10,11].

Toxic and flammable gases such as $\mathrm{CO}, \mathrm{SO}_{2}, \mathrm{NH}_{3}$ and $\mathrm{H}_{2}$ are commonly used and released from industrial plants. With respect to sensing applications, the interaction between the gases, the target gases, and CPs can be divided into two types: either the conductivity increases or decreases depending on both the undoped/doped state of the CPs and the electrophilic/nucleophilic behavior of the target gases [6,11-13]. Conductive polymers such as polypyrrole [14], polyaniline [15,16], polyanilinecarboxylated PVC composite [17], and polyaniline/epoxy resin (SU-8) composite [18] have been investigated as $\mathrm{NH}_{3}$ sensors.

To induce or enhance the interaction between CPs and the target gases, zeolite molecular sieves have been employed [19] due to their nanometric sized channel systems that provide size and shapeselective properties. The adsorption properties of zeolite depend on the zeolite type, the pore size, temperature, and the type of cation residing in the pore. There are two well-known mechanisms for the selective adsorption of zeolites [20]. First, the molecular sieve property, whereby molecules small enough to pass through are adsorbed while larger molecules are not. Second, the zeolite chemical composition; $\mathrm{Si} / \mathrm{Al}$ ratio is the major factor controlling the hydrophilic/hydrophobic properties of materials. The introduction of specific cations, by using the cation exchange method, can dramatically alter gas adsorption properties.

In order to fabricate a sensor with good selectivity which can be operated at room temperature, a conductive polymer and a zeolite are mixed together to combine the advantages of these two materials. In this work, we propose the fabrication of poly(p-phenylene)/zeolite composites for use as an ammonia gas sensor. ZSM-5 zeolite is used as an absorbent. The porous ZSM-5 zeolite induces target gas to contact with low porosity conductive poly(p-phenylene). The effects of ammonia concentration, zeolite content, and cation types, including $\mathrm{H}^{+}, \mathrm{Na}^{+}, \mathrm{K}^{+}$and $\mathrm{NH}_{4}^{+}$on the electrical conductivity response towards ammonia are systematically investigated.

\section{Experimental}

\subsection{Materials}

Benzene (AR grade) was obtained from Thai Aromatic Co., Ltd and was freshly distilled before use as the monomer. Aluminium chloride and cupric chloride (AR grades, Riedel-de Haen) were used as the oxidant and the catalyst for the synthesis of poly(p-phenylene), respectively. Hydrochloric acid (AR grade, JT Baker) was used as the washing solution. Ferric chloride (AR grade, Fisher Scientific) and ethanol (99.5\%, Carlo Erba) were used in the doping of PPP. ZSM-5 zeolite $\left(\mathrm{SiO}_{2} / \mathrm{Al}_{2} \mathrm{O}_{3}: 23\right)$ in powder form was purchased from Zeolyst International. Sodium chloride, potassium chloride and 
lithium chloride, (AR grade, Ajax Finechem), were used in the cation exchange processes. Nitrogen (99\%, TIG) and ammonia gas (99.99\%, Poontaweporn Limited Partnership) carbon monoxide (0.1\%, TIG) and hydrogen (99.999\%, TIG) were used to investigate the electrical conductivity responses of the composites.

\subsection{Poly(p-phenylene) Synthesis}

Poly( $p$-phenylene) was chemically synthesized via the oxidative polymerization method described elsewhere [21,22]. The reaction between benzene, anhydrous aluminum chloride, and anhydrous cupric chloride at a mole ratio of 8:2:1 was carried out at $32-37{ }^{\circ} \mathrm{C}$ under a nitrogen atmosphere for $3 \mathrm{~h}$. The mixture was subsequently cooled and added to ice-cold $18 \%$ hydrochloric acid. After filtration, the PPP particles were washed several times with boiling acid solution and with boiling distilled water and then dried at $110^{\circ} \mathrm{C}$ for $3 \mathrm{hr}$.

\subsection{Poly(p-phenylene) Doping}

The doping process of PPP with $\mathrm{FeCl}_{3}$ in our work was adapted from Shiga et al. [23] and performed by suspending the PPP particles in $100 \mathrm{~mL}$ of $\mathrm{FeCl}_{3}$-ethanol solutions at $60{ }^{\circ} \mathrm{C}$ in a $50: 1$ mole ratio between the dopant and PPP monomer. After the mixture was filtered, the doped PPP was dried at ambient temperature under vacuum for $12 \mathrm{~h}$. The obtained doped PPP is coded as 50:1 dPPP and the undoped PPP as uPPP.

\subsection{Preparation of the Zeolitic Materials}

The starting ZSM-5 material with $\mathrm{SiO}_{2} / \mathrm{Al}_{2} \mathrm{O}_{3}$ ratios of 23 was in an ammonium form $\left(\mathrm{NH}_{4} \mathrm{ZSM}-5\right)$. The cation exchange process was carried out by using the conventional method [24]: a mixture of $1 \mathrm{~g}$ zeolite per $100 \mathrm{~mL}$ of $0.3 \mathrm{M} \mathrm{NaCl}$ solution was stirred at $90{ }^{\circ} \mathrm{C}$ for $1 \mathrm{hr}$, then filtered, and washed with distilled water several times. After the cation-exchanged zeolite was dried, the zeolite was calcined at $550{ }^{\circ} \mathrm{C}$ for $3 \mathrm{~h}$ with a heating rate of $1{ }^{\circ} \mathrm{C} / \mathrm{min}$.

\subsection{Composite Preparation}

PPP powder was ground, sieved with $53 \mu \mathrm{m}$ sieve, and then dried prior to being mechanically mixed with dried zeolite powder at various zeolite amounts: $10 \%, 20 \% 30 \%$ and $40 \% \mathrm{v} / \mathrm{v}$, in order to investigate the effect of zeolite content. The dry mixed composites were subsequently pressed into pellets with a diameter of $15 \mathrm{~mm}$ and a nominal thickness of $0.4 \mathrm{~mm}$, using a hydraulic press machine at a pressure of $\sim 5 \mathrm{kN}$.

\subsection{Characterization}

A Fourier transform infrared spectrometer (FTIR Nicolet, Nexus 670) was used to identify the PPP's functional groups and its interaction with CO. PPP powder or PPP/zeolite powder were mixed with optical grade $\mathrm{KBr}$ (Carlo Erba Reagent) and compressed into a disc shape. The spectrometer was operated in the transmission mode averaging 20 scans at a resolution of $4 \mathrm{~cm}^{-1}$, covering a wave number range of $400-4,000 \mathrm{~cm}^{-1}$. The thermal stability of undoped and 50:1 doped PPP was 
investigated by using a thermogravimetric analyzer (Dupont, TGA 2950). An X-ray diffractometer (XRD Phillips, Rigaku) was used to examine the crystallinity of PPP and the crystal order of the zeolite. A scanning electron microscope (SEM JEOL, JSM 5200) was used to observe the morphology of sample materials. The surface areas and the pore volumes of ZSM-5 zeolites were measured by using a surface area analyzer (Quantachrome, Autosorb-1). An atomic absorption analyzer, AAA, (Varian, Spectre AA 300) was used to determine the exact amount of silicon-aluminium containing in the zeolite and the contents of the exchanged cations in terms of cation exchange level. The $\mathrm{NH}_{3}-\mathrm{TPD}$ thermogram (TPDRO, 1100) of the zeolite was measured to examine the $\mathrm{NH}_{3}$ desorption. .

\subsection{Electrical Conductivity and Gas Measurements}

The bulk electrical conductivity of PPP pellets under exposure to air, $\mathrm{N}_{2}$ and $\mathrm{NH}_{3}$ were measured by using a custom made two-point probe which was connected to a voltage supplier (Keithley, 6517A) in which its voltage was varied and the current was measured in the linear Ohmic regime. Therefore, the electrical conductivity can be calculated from the equation: $\sigma=(I / K V t)$, where $I$ is the measured current (A), $V$ is the applied voltage (V), $t$ is the thickness, and $K$ is the geometric correction factor of the two-point probe which can be determined by calibrating the probe with a silicon wafer possessing a known resistivity value. The electrical conductivity response and sensitivity of the composites were determined by following the equations: $\Delta \sigma=\sigma_{\mathrm{NH}_{3}}-\sigma_{\mathrm{N}_{2} \text { initial }}$ and $\Delta \sigma / \sigma_{\mathrm{N}_{2} \text { initial }}$, respectively. The twopoint probe was located in a gas chamber connected upstream with a mixing gas chamber. $\mathrm{NH}_{3}-\mathrm{N}_{2}$ mixture of $20 \% \mathrm{v} / \mathrm{v}$ was initially injected into the mixing chamber at the pressure of $1.1 \mathrm{~atm}$. Then it was diluted by injecting with an equal volume of $\mathrm{N}_{2}$ to obtain the pressure of $2.2 \mathrm{~atm}$. Half of the mixture was then transferred to the measurement chamber, which now contains $10 \% \mathrm{v} / \mathrm{v} \mathrm{NH} \mathrm{NH}_{3}-\mathrm{N}_{2}$ at a pressure of $1.1 \mathrm{~atm}$. Other mixtures with lower $\mathrm{NH}_{3}$ concentrations were obtained by successive dilutions with $\mathrm{N}_{2}$ in the mixing gas chamber. In all measurements, the gas chamber temperature was maintained at $27 \pm 1{ }^{\circ} \mathrm{C}$ and the gas pressure was $1.1 \mathrm{~atm}$ to prevent external air from leaking in.

\section{Results and Discussion}

\subsection{Characterization of Poly(p-phenylene)}

The infrared spectrum of the synthesized undoped PPP (UPPP) shows a very intense band at $805 \mathrm{~cm}^{-1}$ and moderate intensity bands at 999, 1,396, and $1,479 \mathrm{~cm}^{-1}$, corresponding to the para aromatic substitution. Peaks at 763 and $695 \mathrm{~cm}^{-1}$ can be assigned to the mono substitution [21,25]. For 50:1 doped PPP, additional adsorption peaks appear at 1,545 and $1,180 \mathrm{~cm}^{-1}$, due to the intrinsic vibration of the polymer chain in the doped state [26-28].

UV-Vis absorption spectra of undoped poly(p-phenylene) show a reflectance peak at $350 \mathrm{~nm}$ corresponding to the $\pi-\pi^{*}$ transition of the benzenoid ring [29]. After doping, the reflectance peak of the $\pi-\pi^{*}$ transition of the benzenoid ring shifts to $300-400 \mathrm{~nm}$ [29].

Thermograms under air of both uPPP and 50:1 dPPP display single step decompositions at $569^{\circ} \mathrm{C}$ and $480{ }^{\circ} \mathrm{C}$, respectively. This demonstrates that uPPP is both thermally and thermooxidatively stable [21]. dPPP is less thermally stabile since the doping induces the defects in the polymer chain; yet our synthesized dPPP can still withstand heat up to $400{ }^{\circ} \mathrm{C}$. 
A XRD pattern of uPPP shows a high degree of crystallinity accompanied by $d$-spacing values of 4.53 , 3.63, and $3.24 \AA$. The most intense $d$-spacing is at $4.53 \AA$, corresponding to the length of the phenyl unit $[21,30]$. This suggests that the rings are very nearly coplanar. This sharp peak representing crystallinity decreases upon further doping. The mean particle size and the density of dPPP are $33.61 \pm 0.18 \mu \mathrm{m}$ and $1.3273 \pm 0.0011 \mathrm{~g} / \mathrm{cm}^{3}$, respectively.

\subsection{Characterization of ZSM-5 and Composites}

The mean particle size of ZSM-5 from the particle size analysis is $5.46 \pm 0.01 \mu \mathrm{m}$, comparable to that obtained from the SEM image. The density of the zeolite is $1.9739 \pm 0.0004 \mathrm{~g} / \mathrm{cm}^{3}$. From the atomic absorption spectroscopy data (AAS), the numbers of moles of Si and Al in ZSM-5 can be calculated and reported in terms of $\mathrm{Si} / \mathrm{Al}$ ratio which is equal to 12.67 . The amounts of $\mathrm{Na}^{+}$and $\mathrm{K}^{+}$ exchanged in the zeolites are tabulated in Table 1.

Table 1. The cation exchange levels of $\mathrm{NH}_{4} \mathrm{ZSM}-5(23)$ with $\mathrm{Na}^{+}$and $\mathrm{K}^{+}$present as the cations.

\begin{tabular}{cccc}
\hline Cation & $\begin{array}{c}{\left[\mathrm{Al}_{3}{ }^{+}\right]} \\
\text {(mmol/g zeolite) }\end{array}$ & $\begin{array}{c}\text { [Cation] } \\
\text { (mmol/g zeolite) }\end{array}$ & \% Exchange \\
\hline $\mathrm{Na}^{+}$ & 1.0978 & 1.0674 & 97.23 \\
$\mathrm{~K}^{+}$ & 1.0978 & 1.0576 & 96.34 \\
\hline
\end{tabular}

The specific surface areas of ZSM-5 containing various cation types $\left(\mathrm{Na}^{+}, \mathrm{K}^{+}, \mathrm{NH}_{4}^{+}\right.$and $\left.\mathrm{H}^{+}\right)$are shown in Table 2. Thus, the surface areas and the pore volumes of the zeolites vary according to the cation size.

Table 2. Surface areas and pore volumes of the zeolites.

\begin{tabular}{|c|c|c|}
\hline Zeolite & $\begin{array}{c}\text { BET surface area } \\
\left(\mathrm{cm}^{2} / \mathrm{g}\right)\end{array}$ & $\begin{array}{c}\text { Pore volume } \\
\left(\mathrm{cm}^{3} / \mathrm{g}\right)\end{array}$ \\
\hline $\mathrm{NH}_{4} \mathrm{ZSM}-5(23)$ & $290.1 \pm 0.85$ & $0.1819 \pm 0.0031$ \\
\hline HZSM-5(23) & $332.6 \pm 6.51$ & $0.2075 \pm 0.0006$ \\
\hline NaZSM-5(23) & $283.1 \pm 8.63$ & $0.1759 \pm 0.0112$ \\
\hline KZSM-5(23) & $273.3 \pm 1.34$ & $0.1663 \pm 0.0074$ \\
\hline
\end{tabular}

The $\mathrm{NH}_{3}$-TPD profiles in Figure 1 indicate the acidic properties of the zeolites with different cations. The acidic activity follows this order: $\mathrm{H}^{+}>\mathrm{Na}^{+}>\mathrm{K}^{+}$, consistent with that of previous work [31].

Umar et al., studied the effect of cation exchange to the acid sites, the activity, and the selectivity of a dealuminated faujasite. The acidic properties were determined by $\mathrm{NH}_{3} / \mathrm{TPD}$ measurements. The deactivating effect of individual cations was a strong function of size. The acidic activity follows the order $\mathrm{H}^{+} \sim \mathrm{Mg}^{2+} \sim \mathrm{Li}^{+}>\mathrm{Na}^{+}>\mathrm{K}^{+}[31]$. 
Figure 1. $\mathrm{NH}_{3}-\mathrm{TPD}$ thermograms of ZSM-5(23) of various cation types.

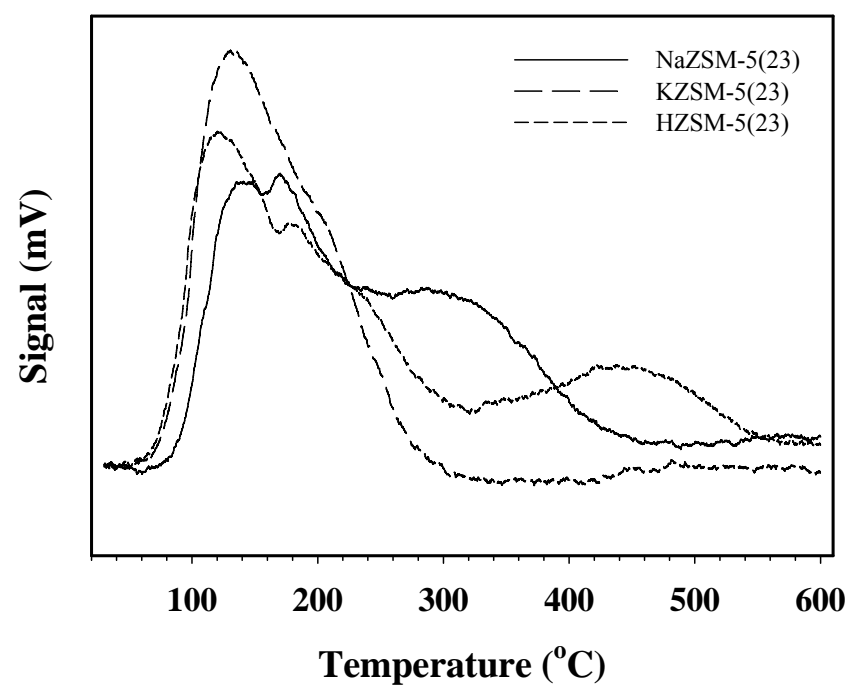

Figure 2a-f shows SEM images of 50:1dPPP, ZSM-5(23), and 50:1dPPP/ZSM-5(23) composites of various zeolite amounts. ZSM-5 zeolite particles possess irregular crystal shapes and appear to be inhomogeneously dispersed in the conductive polymer matrix.

Figure 2. Morphology of dPPP particles, ZSM-5(23) powder, and dPPP(\%v/v)/zeolite composites: a) 50:1dPPP at 1000x; b) ZSM-5(23) at 1500x; c) 50:1dPPP(90)/NaZ23 at $1000 \mathrm{x}$; d) $50: 1 \mathrm{dPPP}(80) / \mathrm{NaZ} 23$ at $1000 \mathrm{x}$; e) $50: 1 \mathrm{dPPP}(70) / \mathrm{NaZ} 23$ at $1000 \mathrm{x}$; and f) $50: 1 \mathrm{dPPP}(60) / \mathrm{NaZ23}$ at $1000 \mathrm{x}$.

(a)

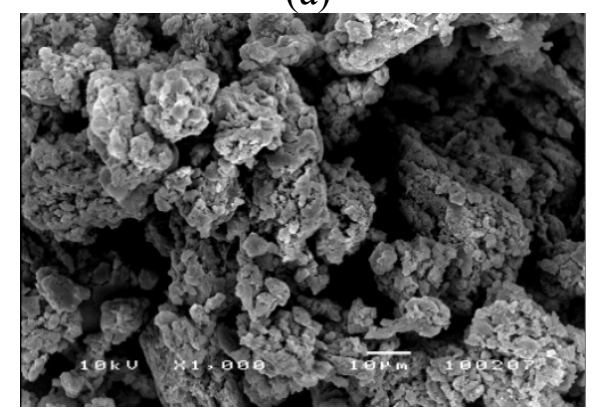

(c)

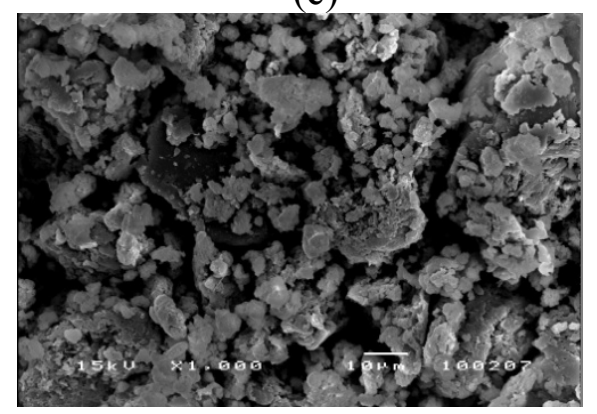

(b)

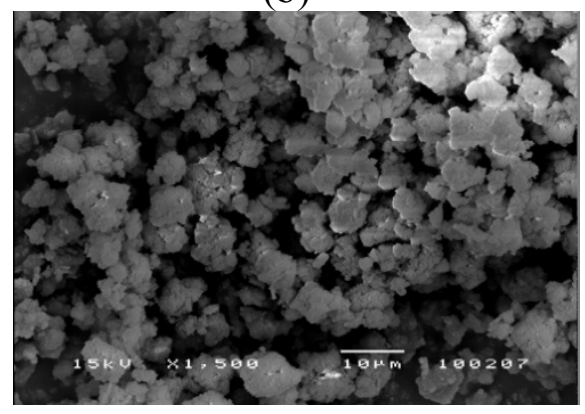

(d)

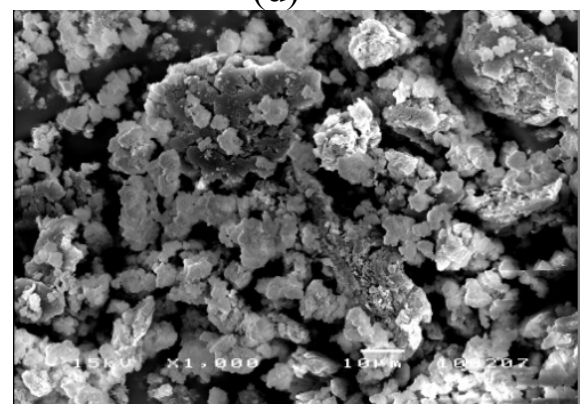


Figure 2. Cont.

(e)

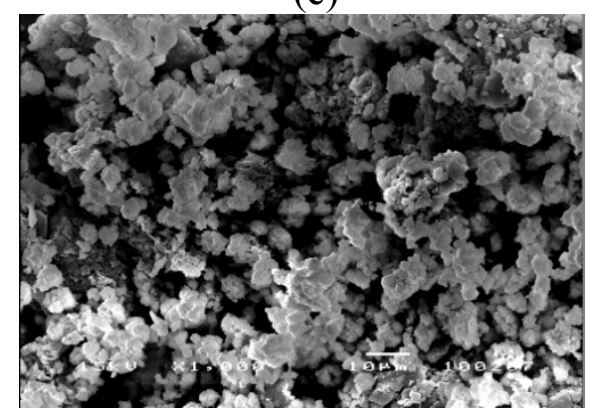

(f)

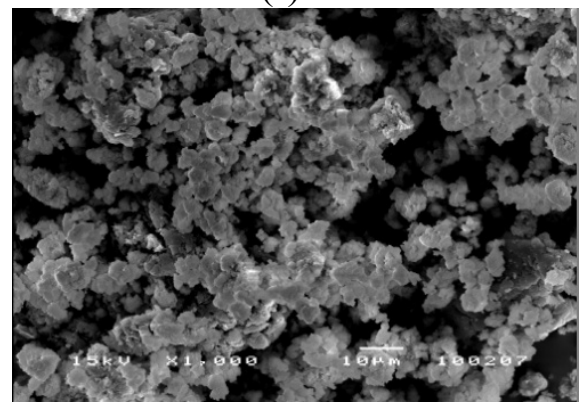

\subsection{Electrical Conductivity in Air and $N_{2}$}

The specific electrical conductivity measurements of uPPP, 50:1 dPPP, and its composites under air and $\mathrm{N}_{2}$ atmospheres were carried out at $28 \pm 1{ }^{\circ} \mathrm{C}$ and at $1 \mathrm{~atm}$. The specific electrical conductivity of uPPP in air is $(1.17 \pm 0.07) \times 10^{-5} \mathrm{~S} / \mathrm{cm}$, as shown in Figure 3. Doping uPPP increases the electrical conductivity in air by several orders of magnitude, up to $0.87 \pm 0.42 \mathrm{~S} / \mathrm{cm}$, as shown in this figure.

Figure 3. $\sigma$ vs. zeolite $\%$ volume content of 50:1dPPP/NaZSM-5(23) composites in air and $\mathrm{N}_{2}$ at $1 \mathrm{~atm}$ and $(28 \pm 1){ }^{\circ} \mathrm{C}$; data shown were obtained from at least two samples.

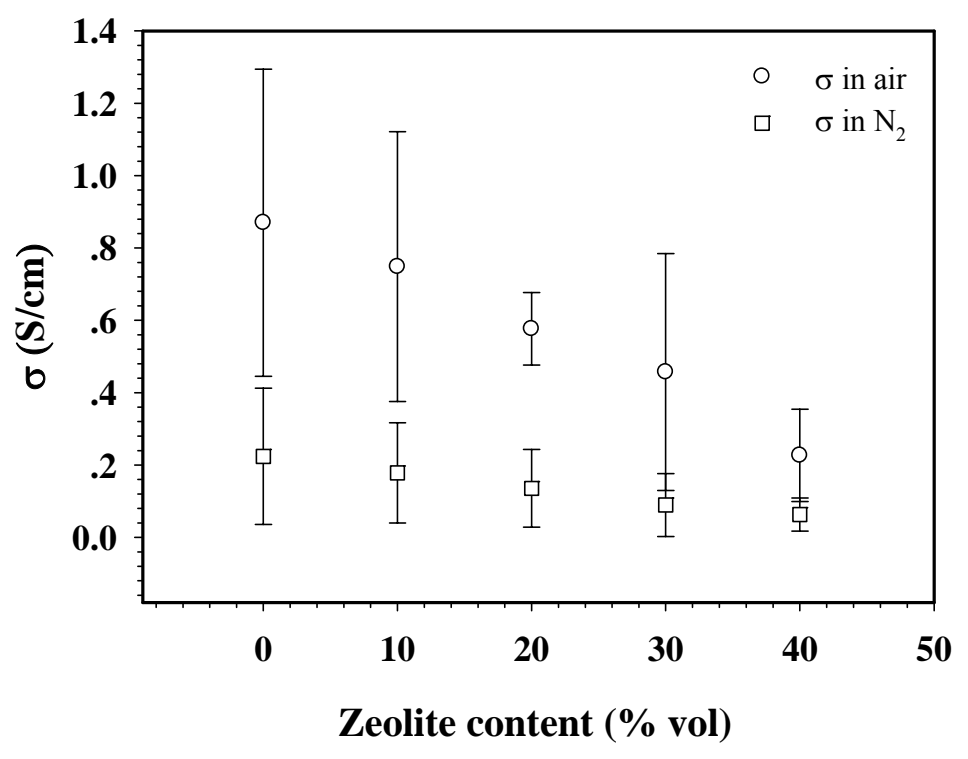

The increase in electrical conductivity is due to the oxidation of the $\pi$-conjugated system of the conductive polymer. Doping with $\mathrm{FeCl}_{3}$ causes the increase in electrical conductivity, and it converts the brown insulating PPP powder into black conductive PPP. The counter ion or the dopant species of dPPP $\mathrm{FeCl}_{4}{ }^{-}$occurs from the reduction of $\mathrm{Fe}^{3+}$ to $\mathrm{Fe}^{2+}$ and the oxidation of the $\pi$-system of PPP [32]. After introducing the zeolite into the polymer matrix, the electrical conductivity in air decreases to $0.22 \pm 0.13 \mathrm{~S} / \mathrm{cm}$ (Figure 3) with increasing zeolite content from $0 \%$ to $40 \%$, because of the reduction in the number of polarons. Under a $\mathrm{N}_{2}$ atmosphere, it can be seen from Figure 3 that the electrical conductivity is less than that in air at any zeolite content. This is due to the presence of moisture in air which can induce an increase in electrical conductivity. 


\subsection{Electrical Conductivity Response to $\mathrm{CO}$ and $\mathrm{H}_{2}$}

The electrical conductivity response $\left(\Delta \sigma=\sigma_{\text {gas }}-\sigma_{N_{2}}\right)$ is identified as the difference in the steady state electrical conductivities of the sample under target gas and under $\mathrm{N}_{2}$ exposure at $28 \pm 1{ }^{\circ} \mathrm{C}$ and at 1 atm. Because various composites possessing different initial electrical conductivity values, the sensitivity $\left(\Delta \sigma / \sigma_{N_{2}}\right)$, defined as the ratio of the electrical conductivity response and the electrical conductivity under pure $\mathrm{N}_{2}$ exposure, will be used in comparing responses of various composites. . The electrical conductivity sensitivities towards the target gases $\left(\mathrm{CO}, \mathrm{H}_{2}\right.$, and $\left.10 \% \mathrm{NH}_{3}\right)$ are investigated and reported below.

Under CO atmosphere, dPPP shows a very small positive response with a sensitivity of $2.1 \times 10^{-2}$, as tabulated and shown in Table 3. CO behaves like an electrophilic gas, $\mathrm{CO}$ molecules are expected to withdraw electrons from dPPP, the p-type doped conductive polymer consisting of polarons and bipolarons, causing an increase in electrical conductivity [33,34]. Unlike the CO-polyaniline interaction, the CO-dPPP interaction is relatively weak with a much lower sensitivity. Therefore, it can be summarized there is no apparent interaction between dPPP and CO; if there is any interaction it appears to be very weak.

Yamamoto and $\mathrm{Gu}$ studied the effect of ammonia gas on the electrical property of a conducting polymer. The electrical conductivity of the PPP film increased by several orders of magnitude when exposed to $\mathrm{NH}_{3}$. The change in electrical conductivity took place relatively fast and was reversible. When the partial pressure of $\mathrm{NH}_{3}$ was reduced through evacuating the sample chamber, the electrical conductivity of the PPP film decreased in a similar pattern. $\mathrm{NH}_{3}$ acted as an effective doping agent in n-doped PPP. Similar results were obtained when PPP films were exposed to diethylamine and triethylamine [35].

Table 3. Doped PPP samples (dPPP) with their electrical conductivity responses, sensitivities, and temporal responses towards $\mathrm{CO}$, and $\mathrm{H}_{2}$.

\begin{tabular}{|c|c|c|c|c|c|c|c|}
\hline \multirow{2}{*}{ Samples } & \multirow{2}{*}{$\begin{array}{c}t_{i} \\
(\mathbf{m i n})\end{array}$} & \multirow{2}{*}{$\begin{array}{c}t_{r e} \\
(\mathbf{m i n})\end{array}$} & \multicolumn{3}{|c|}{$\sigma(\mathrm{S} / \mathrm{cm})$} & \multirow{2}{*}{$\Delta \sigma(\mathrm{S} / \mathrm{cm})$} & \multirow{2}{*}{$\Delta \sigma / \Delta \sigma_{N_{2}}$} \\
\hline & & & Air & $\mathbf{N}_{2}$ & $\mathrm{CO}$ & & \\
\hline dPPP & 182 & 17 & $\begin{array}{l}(4.37 \pm 0.13) \times \\
10^{-1}\end{array}$ & $\begin{array}{l}(7.41 \pm 0.01) \times \\
10^{-2}\end{array}$ & $\begin{array}{l}(7.55 \pm 0.02) \times \\
10^{-2}\end{array}$ & $\begin{array}{l}(1.37 \pm 0.25) \times \\
10^{-3}\end{array}$ & $\begin{array}{l}(2.08 \pm 0.19) \times \\
10^{-2}\end{array}$ \\
\hline \multirow{2}{*}{ Samples } & \multirow{2}{*}{$\begin{array}{c}t_{i} \\
(\mathrm{~min})\end{array}$} & \multirow{2}{*}{$\begin{array}{c}t_{r e} \\
(\mathbf{m i n})\end{array}$} & & $\sigma(\mathrm{S} / \mathbf{c m})$ & & \multirow{2}{*}{$\Delta \sigma(\mathrm{S} / \mathrm{cm})$} & \multirow{2}{*}{$\Delta \sigma / \Delta \sigma_{N}$} \\
\hline & & & Air & $\mathbf{N}_{2}$ & $\mathbf{H}_{2}$ & & \\
\hline dPPP & 133 & 10 & $\begin{array}{l}(7.56 \pm 0.21) \times \\
10^{-2}\end{array}$ & $\begin{array}{l}(6.00 \pm 0.01) \times \\
10^{-2}\end{array}$ & $\begin{array}{l}(6.01 \pm 0.01) \times \\
10^{-2}\end{array}$ & $\begin{array}{l}(1.66 \pm 2.27) \times \\
10^{-4}\end{array}$ & $\begin{array}{l}(5.14 \pm 2.62) \times \\
10^{-3}\end{array}$ \\
\hline
\end{tabular}

$t_{\mathrm{i}}=$ the induction times, $t_{\mathrm{re}}=$ the recovery time, $\sigma=$ electrical conductivity values in air, $\mathrm{N}_{2}, \mathrm{CO}$, and $\mathrm{H}_{2}, \Delta \sigma=$ the electrical response, and $\Delta \sigma / \Delta \sigma_{\mathrm{N} 2}=$ the electrical conductivity sensitivity, at $T=(28 \pm 1){ }^{\circ} \mathrm{C}$, and at atmospheric pressure.

The sensitivity value of dPPP when exposed to $\mathrm{H}_{2}$ is even smaller, with a positive value of $0.5 \times 10^{-2}$, as shown in Table $3 . \mathrm{H}_{2}$ is a reducing gas [36] and it is weakly nucleophilic; thus, when the sample is exposed to $\mathrm{H}_{2}$, a decrease in the electrical conductivity may be expected. In a certain case, $\mathrm{H}_{2}$ may provide an electrical conductivity enhancement [37]. Our data in Table 3 clearly suggest that dPPP does not interact with $\mathrm{H}_{2}$, due to the weak electron transfer between $\mathrm{H}_{2}$ and dPPP. 


\section{5. dPPP and Electrical Conductivity Sensitivity to NH3: Effect of NH3 Concentration}

Figure 4(a) shows the specific electrical conductivity of $\mathrm{dPPP}(60) / \mathrm{NaZ23}$ vs. time (min) when exposed to $5 \% \mathrm{v}$ of $\mathrm{NH}_{3}$ at $28 \pm 1{ }^{\circ} \mathrm{C}$ and at $1 \mathrm{~atm}$. Under the exposure to $\mathrm{NH}_{3}$, the specific electrical conductivity of $\mathrm{dPPP}(60) / \mathrm{NaZ} 23$ first increases and reaches a maximum value of $0.235 \mathrm{~S} / \mathrm{cm}$ after a $\mathrm{NH}_{3}$ exposure time of $2.90 \mathrm{~min}$, then decreases to a steady state value of $0.03 \mathrm{~S} / \mathrm{cm}$ after the $\mathrm{NH}_{3}$ exposure time of $30 \mathrm{~min}$.

Figure 4(b) shows the specific electrical conductivity of dPPP(60)/NaZ23 vs. time (min) after evacuating $5 \% \mathrm{v} \mathrm{NH}_{3}$ and exposure to $\mathrm{N}_{2}$. The specific electrical conductivity increases from a value of $0.01 \mathrm{~S} / \mathrm{cm}$ to a steady state value of $0.03 \mathrm{~S} / \mathrm{cm}$ after the $\mathrm{N}_{2}$ exposure time of $56 \mathrm{~min}$.

Figure 4. The specific conductivity of $\mathrm{dPPP}(60) / \mathrm{NaZ23}$ vs. time: (a) when exposed to $5 \% \mathrm{v}$ $\mathrm{NH}_{3}$; (b) after evacuating $5 \% \mathrm{v} \mathrm{NH}_{3}$ and exposure to $\mathrm{N}_{2}$, at $28 \pm 1{ }^{\circ} \mathrm{C}$ and at $1 \mathrm{~atm}$.

(a)

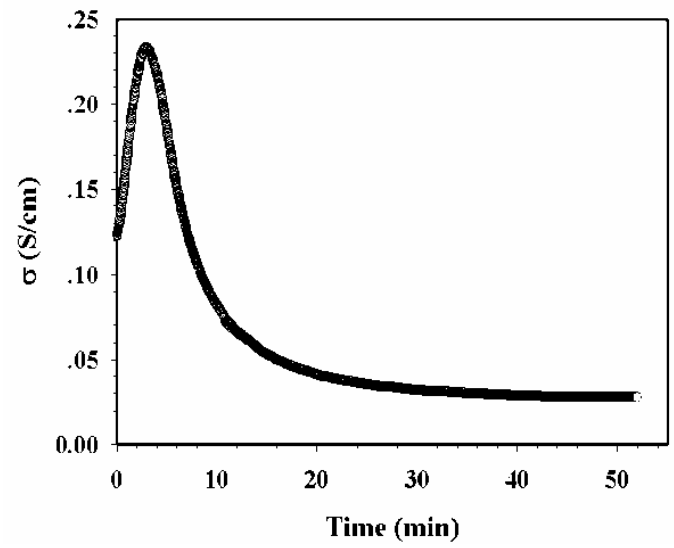

(b)

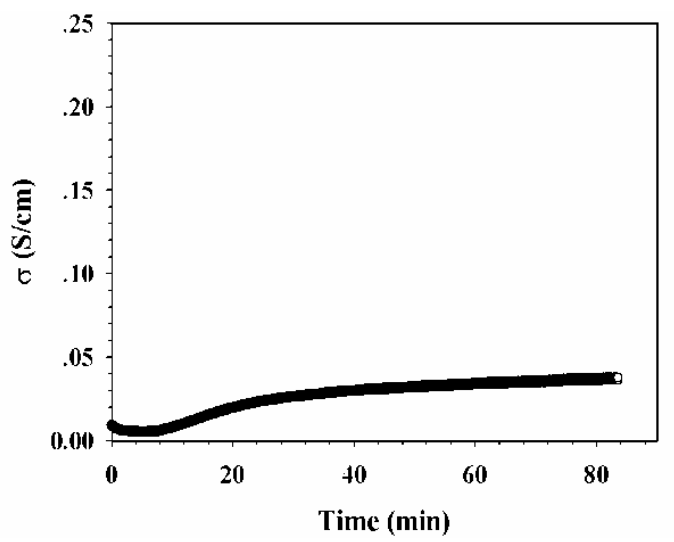

Figure 5 shows the electrical conductivity sensitivity of 50:1 dPPP vs. $\mathrm{NH}_{3}$ concentration at $28 \pm 1{ }^{\circ} \mathrm{C}$ and at $1 \mathrm{~atm}$. The negative sensitivity of 50:1 dPPP increases linearly with increasing $\mathrm{NH}_{3}$ concentration.

Figure 5. $\Delta \sigma / \sigma_{\mathrm{N}_{2}}$ of 50:1 dPPP vs. $\mathrm{NH}_{3}$ concentration at $(29 \pm 1)^{\circ} \mathrm{C}$ and at $1 \mathrm{~atm}$.

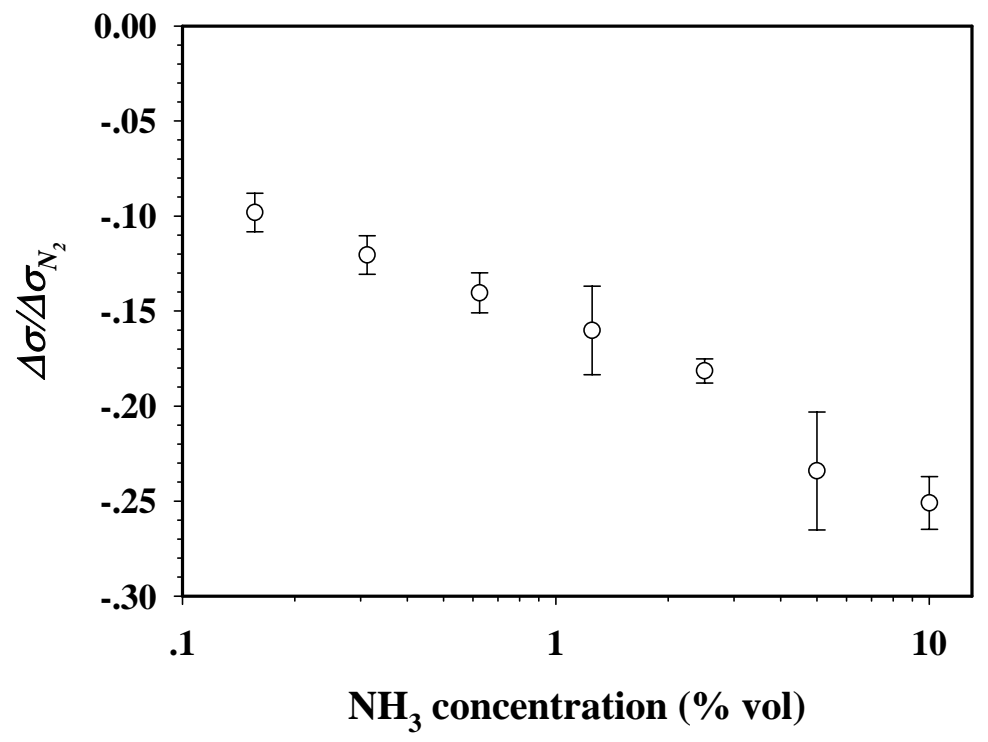


The doping process and the resultant formations of polarons and biporalons induce APPP electrons to be in a higher energy level having lesser stability [37,38]. When dPPP is treated with an electron rich molecule, such as $\mathrm{NH}_{3}$, an electron transfer interaction occurs. Since dPPP is a $p$-type doped conductive polymer and $\mathrm{NH}_{3}$ is a strong nucleophilic gas [12], $\mathrm{NH}_{3}$ tends to give electrons to dPPP causing a decrease in the number of charge carriers, polarons and bipolarons, and the decrease in electrical conductivity; therefore, the negative response is expected and observed. A possible 50:1 dPPP- $\mathrm{NH}_{3}$ interaction is proposed in Figure 6. Here, a $\mathrm{NH}_{3}$ molecule attaches itself to the polaron site through the electrostatic interaction, thus reducing the charge carrier mobility.

Figure 6. Proposed interaction between 50:1 dPPP and $\mathrm{NH}_{3}$.

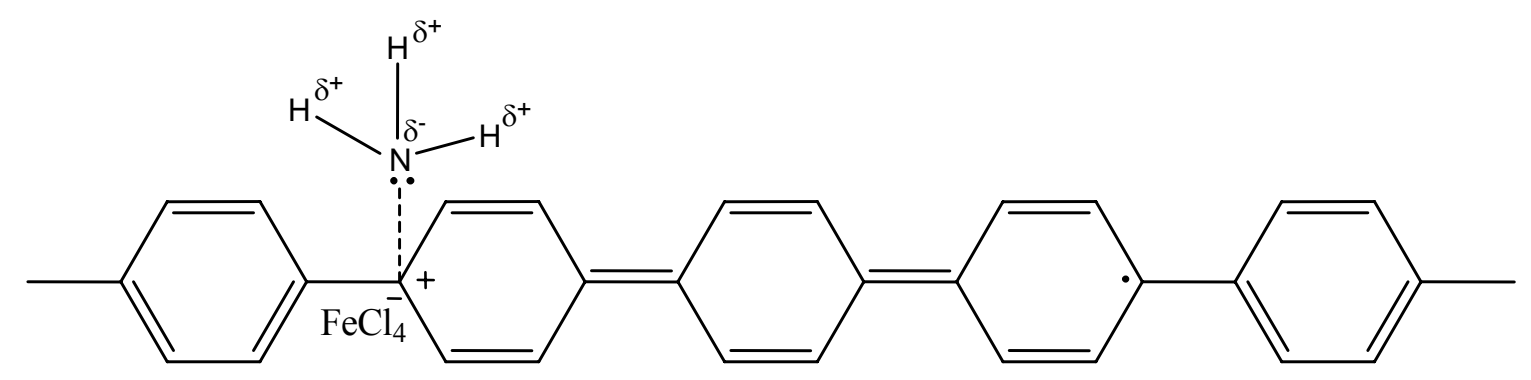

3.6. dPPP/ZSM-5(23) Composites and Electrical Conductivity Response to NH3: Effect of Zeolite Content

The electrical conductivity sensitivities of 50:1dPPP/ZSM-5(23) composites at various $\mathrm{NH}_{3}$ concentrations versus ZSM-5 zeolite content are shown in Figure 7.

Figure 7. $\Delta \sigma / \sigma_{N_{2}}$ of 50:1dPPP/NaZSM-5(23) composites vs. NaZSM-5(23) content when exposed to different $\mathrm{NH}_{3}$ concentrations at $28 \pm 1{ }^{\circ} \mathrm{C}$ and at $1 \mathrm{~atm}$.

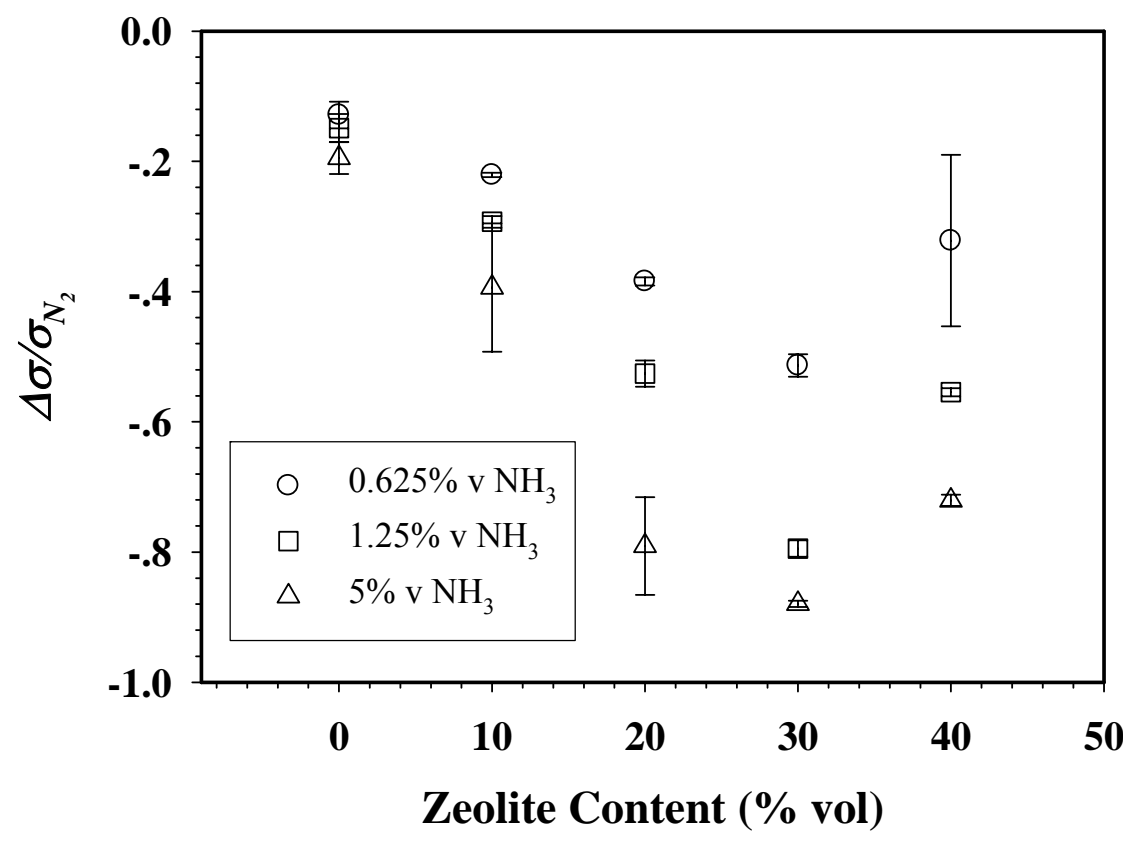


The sensitivities of 50:1 dPPP at $0.625,1.25$, and $5 \% \mathrm{v} \mathrm{NH}$ exposures increase from $-0.140 \pm 0.11$ to $-0.51 \pm 0.02$, from $-0.16 \pm 0.02$ to $-0.79 \pm 0.01$, and from $-0.341 \pm 0.03$ to $-0.88 \pm 0.01$, respectively, as NaZSM-5(23) content increases from 0 to $30 \% \mathrm{v}$. This is because a composite with a higher zeolite content allows more $\mathrm{NH}_{3}$ molecules to adsorb and to diffuse deeper into the composites, thus promoting the $\mathrm{NH}_{3}$-dPPP interaction [35]. Beyond this volume fraction of $40 \% \mathrm{v}$ zeolite, the sensitivities decrease to $-0.32 \pm 0.13,-0.55 \pm 0.01$ and $-0.73 \pm 0.01$ for the $0.625,1.25$ and $5 \% \mathrm{vH}_{3}$ exposures, respectively. In the present case of mechanically mixed systems, the decrease in sensitivity with increasing zeolite content is due to the reduction in the number of available active sites on dPPP for $\mathrm{NH}_{3}$ to interact as zeolite content increases.

\section{7. dPPP/ZSM-5(23) Composites and Electrical Conductivity Response to $\mathrm{NH}_{3}$ : Effect of Cation Type}

We investigate next on the influence of the cation type on the sensitivity of the conductive polymer/zeolite composites. Four cations were chosen: (1) $\mathrm{Na}^{+}$; (2) $\mathrm{K}^{+}$, both cations are very common and we obtain $100 \%$ exchange by the traditional cation exchange process; (3) $\mathrm{NH}_{4}^{+}$, which is the original cation in the zeolite, and (4) $\mathrm{H}^{+}$, this form of ZSM-5(23) is accomplished by the decomposition of the ammonium form. To avoid the effect of zeolite content which may be predominant over the effect of cation type, we fixed the zeolite volume fraction to be at 10\%v. 50:1 dPPP composites, containing $10 \% \mathrm{v}$ of ZSM-5(23) having four different cations $\mathrm{Na}^{+}, \mathrm{K}^{+}, \mathrm{NH}_{4}{ }^{+}$, and $\mathrm{H}^{+}$, are coded as 50:1 dPPP(90)/NaZ23, 50:1 dPPP(90)/KZ23, 50:1 $\mathrm{dPPP}(90) / \mathrm{NH}_{4} \mathrm{Z} 23$ and 50:1 $\mathrm{dPPP}(90) / \mathrm{HZ} 23$, respectively. Figure 8 shows the electrical conductivity sensitivities of 50:1 dPPP, 50:1 dPPP(90)/KZ23, 50:1 dPPP(90)/NaZ23, 50:1 dPPP(90)/NH $\mathrm{NH}_{4} 23$ and 50:1 dPPP(90)/HZ23; they are $-0.14 \pm 0.01,-0.13 \pm 0.005,-0.22 \pm 0.003,-0.36 \pm 0.016$ and $-0.36 \pm 0.62$, respectively.

Figure 8. $\Delta \sigma / \sigma_{N_{2}}$ of 50:1 $\mathrm{dPPP}$ and 50:1 dPPP(90)/ZSM-5(23) composites of various cation types when exposed to $0.625 \% \mathrm{vH}_{3}$, at $(28 \pm 1){ }^{\circ} \mathrm{C}$ and at $1 \mathrm{~atm}$.

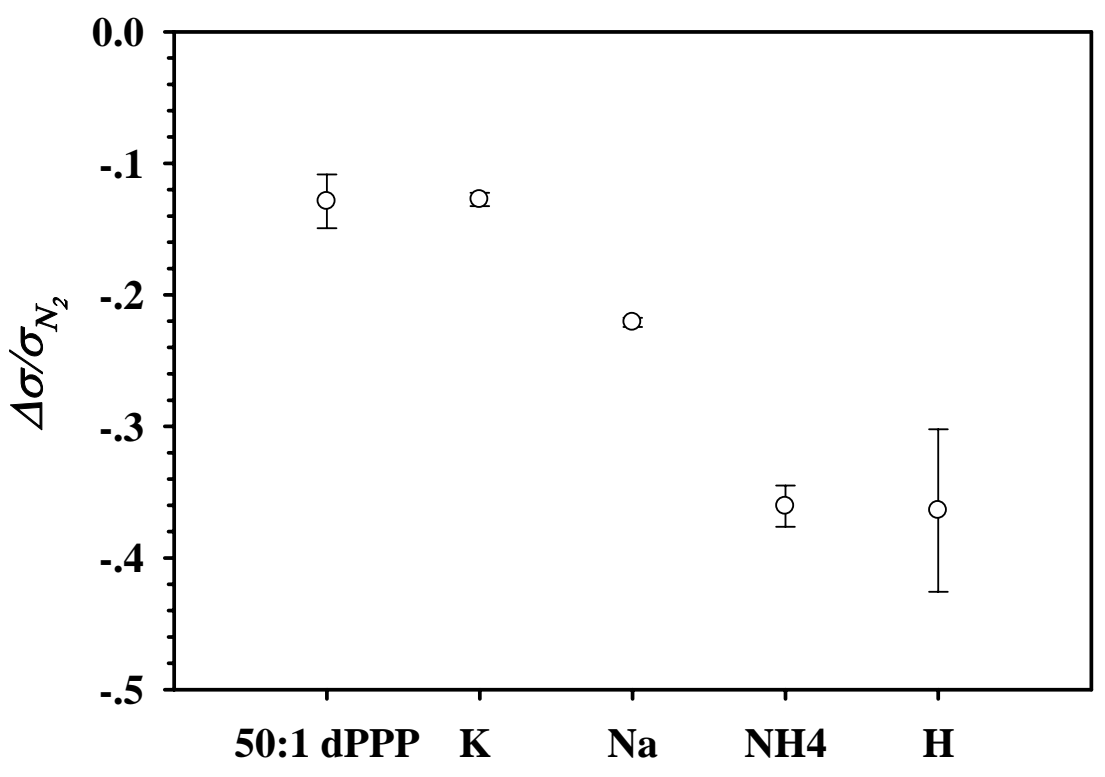

Cation

Since $\mathrm{Na}^{+}$is a common cation, it is used as a basis for the comparison. The sensitivity of composite is remarkably increased when the cation is replaced by either $\mathrm{H}^{+}$or $\mathrm{NH}_{4}{ }^{+}$as the balancing cations in 
the zeolite. This is due to the adsorption property of $\mathrm{NH}_{3}$ onto ZSM-5. The sensitivity of the composites apparently increases with the acidity of the zeolite, shown by the $\mathrm{NH}_{3}$-TPD profiles (Figure 1), the surface area and the pore volume (Table 2). H-ZSM-5 with the highest acidity, the surface area, and the pore volume, providing a more favorable $\mathrm{NH}_{3}$ adsorption, resulting in the highest sensitivity. $\mathrm{NH}_{4}$-ZSM-5 has nearly the same sensitivity value to that of H-ZSM-5, with a lower acidity, surface area and pore volume. On the other hand, the addition of K-ZSM-5 into the dPPP matrix does not improve the sensitivity, instead it causes a slight sensitivity reduction. $\mathrm{NH}_{3}$ does not prefer to adsorb on K-ZSM-5 due to its lower acidity, surface area, and pore volume. The addition of the zeolite merely serves to decrease the number of dPPP active sites available. Hence, the KZSM-5 composite has an even lesser sensitivity than that of pure dPPP.

\subsection{FTIR Investigations of Interactions of Adsorbed $\mathrm{NH}_{3}$}

The interaction of $\mathrm{NH}_{3}$ and the active sites of dPPP, NaZSM-5(23) and their composites are investigated via FTIR spectroscopy under pressure 1 atm and at $28 \pm 1{ }^{\circ} \mathrm{C}$. The FTIR spectra of 50:1 dPPP before, during, and after the $\mathrm{NH}_{3}$ exposure are shown in Figure 9.

Figure 9. FT-IR spectra of 50:1 dPPP: (A) before; (B) during; and (C) after $\mathrm{NH}_{3}$ exposure at $(28 \pm 1){ }^{\circ} \mathrm{C}$ and at $1 \mathrm{~atm}$.

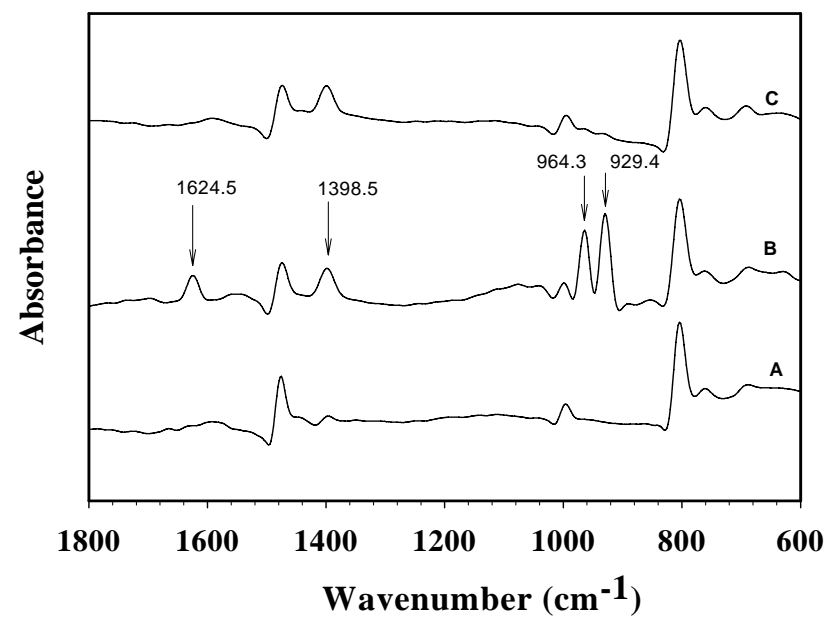

Under $\mathrm{NH}_{3}$ exposure, FTIR spectra were taken every five minutes for a duration of 60 min; each FTIR spectrum has the same patterns but with different intensities evolving in time. Peaks at 929.4, 964.3 , and $1,624.5 \mathrm{~cm}^{-1}$ belong to the vibrations of $\mathrm{NH}_{3}$ molecules, and a peak at $1,398.5 \mathrm{~cm}^{-1}$ can be assigned to the vibration of $\mathrm{NH}_{4}^{+}$molecules [40] or the para aromatic substitution of dPPP [21]. The first bands are slightly different from those of free $\mathrm{NH}_{3}\left(931.58,968.08,1,627.5 \mathrm{~cm}^{-1}\right)$. The last band is diatinct from that of the free $\mathrm{NH}_{4}^{+}\left(1,397 \mathrm{~cm}^{-1}\right)$ [40] or the para-aromatic substitution of dPPP band $\left(1,396 \mathrm{~cm}^{-1}\right)$ [21]. The presence of the bands for $\mathrm{NH}_{3}$ and $\mathrm{NH}_{4}{ }^{+}$suggest both of the $\mathrm{C}^{+} \ldots \mathrm{NH}_{3}$ interaction (Figure 5) and the $\mathrm{FeCl}_{4}{ }^{-} \ldots \mathrm{NH}_{4}{ }^{+}$interaction taking place. After replacing $\mathrm{NH}_{3}$ with $\mathrm{N}_{2}$, the bands at $929.4,964.3,1,398.5 \mathrm{~cm}^{-1}$ still remain in the $\mathrm{dPPP} / \mathrm{NH}_{3}$ FTIR spectrum. The ammonia-dPPP interactions are thus irreversible, consistent with the irreversible conductivity response observed when replacing $\mathrm{NH}_{3}$ with $\mathrm{N}_{2}$. 
Figure 10 shows the FTIR spectra of NaZSM-5 before, during, and after the $\mathrm{NH}_{3}$ exposure. The bands at 916.0 and $950 \mathrm{~cm}^{-1}$ appear after the $\mathrm{NH}_{3}$ exposure; and they disappear when $\mathrm{NH}_{3}$ is replaced by $\mathrm{N}_{2}$. These peaks are due to the $\mathrm{NH}_{3}$ vibrations, with shifts in the frequency from those of the free $\mathrm{NH}_{3}$ (931.58 and $968.09 \mathrm{~cm}^{-1}$ ), representing with the Lewis sites [40]. There is no significant difference in the band patterns before and after the exposure to $\mathrm{NH}_{3}$; thus, the interaction between $\mathrm{NH}_{3}$ and NaZSM-5 is reversible based on the FTIR spectrum.

Figure 10. FT-IR spectra of NaZSM-5(23); A before; B during; $\mathbf{C}$ after $\mathrm{NH}_{3}$ exposure at $(28 \pm 1)^{\circ} \mathrm{C}$ and at $1 \mathrm{~atm}$.

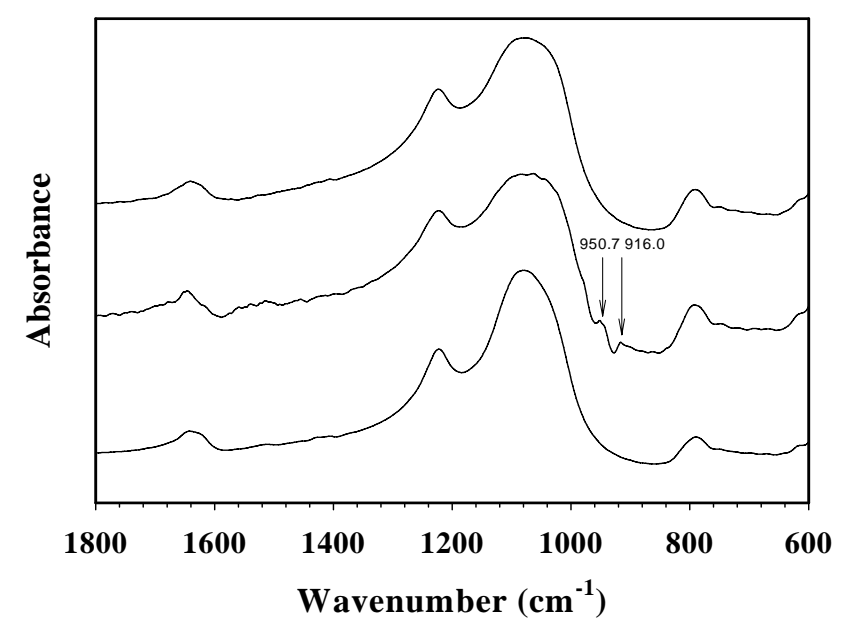

\section{Conclusions}

Doped PPP with $\mathrm{FeCl}_{3}$ is investigated as a $\mathrm{NH}_{3}$ gas sensing material due to its negative electrical conductivity response. The electrical conductivity sensitivity of 50:1 dPPP toward $\mathrm{NH}_{3}$ decreases with increasing $\mathrm{NH}_{3}$ concentration and can be further improved by introducing a ZSM-5 zeolite into the dPPP matrix. The electrical conductivity sensitivity decreases with increasing zeolite content up to $30 \%$. At $40 \%$ zeolite content, the positive response is present at the beginning of the gas exposure and the negative response appears at later times. The effect of cation type is also investigated for various cations: $\mathrm{Na}^{+}, \mathrm{K}^{+}, \mathrm{NH}_{4}{ }^{+}$and $\mathrm{H}^{+}$. The sensitivity of the composites with different cations can be arranged in this order; 50:1 dPPP(90)/KZ23 <50:1 dPPP <50:1 dPPP(90)/NaZ23 <50:1 dPPP(90)/NH4Z23 $<50: 1 \mathrm{dPPP}(90) / \mathrm{HZ} 23$. The order of the sensitivity with various cation types can be described in terms of the acidic properties, the pore size and the surface area. The 50:1 dPPP(90)/HZ23 composite possesses the highest sensitivity of -0.36 as $\mathrm{H}^{+}$has the highest acidity, pore size and surface area, and hence can induce a more favorable $\mathrm{NH}_{3}$ adsorption on the composite. Based on the FTIR spectrum, the $\mathrm{NH}_{3}$-dPPP interaction is irreversible while the $\mathrm{NH}_{3}$-zeolite interaction is reversible.

\section{Acknowledgements}

The authors are thankful to the financial supports from the Conductive and Electroactive Polymers Research Unit, the Korea Foundation for Advanced Studies (KFAS), both from Chulalongkorn University, the Center of Petroleum Petrochemical and Advanced Materials, the Thailand Research Fund (TRF, BRG), and the Royal Thai Government (Budget of Fiscal Year 2551). 


\section{References and Notes}

1. Kaden, H.; Jahn, H.; Berthold, M. Study of the glass/polypyrrole interface in an all-solid-state $\mathrm{pH}$ sensor. Solid State Ionics 2004, 169, 129-133.

2. Migdilski, J.; Blaz, T.; Lewenstam, A. Conducting polymer-based ion-selective electrodes. Anal. Chem. Acta 1996, 322, 141-149.

3. Nohria, R.; Khillan, R.K.; Su, Y.; Dikshit, R.; Lvov, Y.; Varahramyan, K. Humidity sensor based on ultrathin polyaniline film deposited using layer-by-layer nano-assembly. Sens. Actuat. B-Chem. 2006, 114, 218-222.

4. Grennan, K.; Killard, A.J.; Hanson, C.J.; Cafolla, A.A.; Smyth, M.R. Optimisation and characterisation of biosensors based on polyaniline. Talanta 2006, 68, 1591-1600.

5. Persaud, K.C. Polymer in chemical sensing. Materials Today 2005, 8, 38-44.

6. Watcharaphalakorn, S.; Ruangchuay, L.; Chotpattananont, D.; Srivat, A.; Schwank, J. Polyaniline/polyimide blends as gas sensors and electrical conductivity response to $\mathrm{CO}-\mathrm{N}_{2}$ mixtures. Polym. Int. 2005, 54, 1126-1133.

7. Ma, X.; Li, G.; Xu, H.; Wang, M.; Chen, H. Preparation of polythiophene composite film by in situ polymerization at room temperature and its gas response studies. Thin Solid Films 2006, 515, 2700-2704.

8. Ruangchuay, L.; Sirivat, A.; Schwank, J. Polypyrrole/poly(methylmethacrylate) blend as selective sensor for acetone in lacquer. Talanta 2003, 60, 25-30.

9. Vamstrom, C.; Ivaska, A. An electrochemical study of poly(paraphenylene) in conductive polymer bilayer electrodes. J. Electroanal. Chem. 1997, 421, 67-78.

10. Blackwood, D.; Josowicz, M. Work function and spectroscopic studies of interaction between conducting polymers and organic vapors. J. Phys. Chem. 1991, 95, 493-502.

11. Yoshino, K; Gu, H.B. Effect of ammonium gas on electrical property of conductive polymers. $J$. Appl. Phys. 1986, 25, 1064-1068.

12. Collins, G.E.; Buckley, L.J. Conductive polymer coated fabrics for chemical sensing. Synth. Metal. 1996, 78, 93-101.

13. Bhat, N.V.; Gadre, A.P.; Bambole, V.A. Investigation of Electropolymerized polypyrrole composite film: characterization and application to gas sensors. J. Appl. Polym. Sci. 2003, 88, 22-29.

14. Lähdesmäki, I.; Lewenstam, A.; Ivaska, A. A polypyrrole-based amperometric ammonia sensor. Talanta 1996, 43, 125-134.

15. Nicolas, D.D.; Poncin, E.F. Polyaniline as a new sensitive layer for gas sensors. Anal. Chim. Acta 2003, 475, 1-15.

16. Kukla, A.L.; Shirshov, Y.M.; Piletsky, S.A. Ammonia sensors based on sensitive polyaniline films. Sens. Actuat. B 1996, 37, 135-140.

17. Singh, V.; Mohan, S.; Singh, G.; Pandey, P.C.; Prakash. R. Synthesis and characterization of polyaniline-carboxylated PVC composites: application in development of ammonia sensor. Sens. Actuat. B 2008, 132, 99-106.

18. Airoudj, A.; Debarnot, D.; Bêche, B.; Poncin-Epaillard, F. Development of an optical ammonia sensor based on polyaniline/epoxy resin (SU-8) composite. Talanta 2008, 77, 1590-1596. 
19. Soontornworajit, B.; Wannatong, L.; Hiamtup, P.; Niamlang, S.; Chotpattananont, D.; Sirivat, A.; Schwank, J. Induced interaction between polypyrrole and $\mathrm{SO}_{2}$ via molecular sieve 13X. Mat. Sci. Eng. B-Solid 2007, 136, 78-86.

20. Vilaseca, M.; Yague, C.; Coronas, J.; Santamaria, J. Development of QCM sensors modified by $\mathrm{AlPO}_{4}-18$ films. Sens. Actuat. B-Chem. 2006, 117, 143-150.

21. Kovacic, P.; Kyriakis, A. Polymerization of benzene to p-polyphenyl by aluminum chloride-cupric chloride. J. Am. Chem. Soc. 1963, 85, 454-458.

22. Kovacic, P.; Oziomek, J. p-Polyphenyl from benzene-Lewis acid catalyst-oxidant reaction scope and investigation of benzene-aluminum chloride-cupric chloride system. J. Org. Chem. 1964, 29, 100-104.

23. Shiga, T.; Okada, A.; Kurauchi, T. Electroviscoelastic effect of polymer blends consisting of silicone elastomer and semiconducting polymer particles. Macromolecules 1993, 26, 6958-6963.

24. Kuroda, Y.; Yoshikawa, Y. Characterization of specific $\mathrm{N}_{2}$-adsorption site existing on CuZSM-5 type zeolite: effect of ion-exchange level on adsorption properties. J. Phys. Chem. B 1999, 103, 2155-2164.

25. Aeiyach, S.; Soubiran, P.; Lacaze, P. Influence of the temperature on the structure of poly(pphenylene) (PPP) films formed by electropolymerization of benzene on platinum electrodes in sulphur dioxide medium. Polym. Commun. 1988, 29, 130-131.

26. Yli-Lahti, P.; Stubb, H.; Isotalo, H.; Kuivalainen, P.; Kalervo, L. IR behaviour, conductivity and stability of $\mathrm{FeCl} 3$-doped polyparaphenylene $\left(\mathrm{p}-\mathrm{C}_{6} \mathrm{H}_{4}\right)_{\mathrm{x}}$. Mol. Cryst. Liq. Cryst. 1985, 118, 305-308.

27. Shacklette, L.W.; Eckhardt, H.; Chance, R.R.; Miller, G.G.; Ivory, D.M.; Baughman, R.H. Solidstate synthesis of highly conducting polyparaphenylene from crystalline oligomers. J. Chem. Phys. 1980, 73, 4098-4102.

28. Yaniger, S.I.; Rose, D.J.; McKenna, W.P.; Eyring, E.M. Photoacoustic infrared spectroscopy of doped and undoped poly(p-phenylene). Macromolecules 1984, 17, 2579-2583.

29. Oguma, J., Akagi, K., Shirakawa, H. Synthesis and properties of liquid crystalline poly(pphenylene) and poly(p-phenylenevinylene) derivatives. Synth. Metals 1999, 101, 86-103.

30. Marvel, C.S.; Hartzell, G.E. Preparation and aromatization of poly-1,3-cyclohexadiene. J. Am. Chem. Soc. 1959, 81, 448-452.

31. Kumar, R.; Cheng, W.C.; Rajagopalan, K.; Peters, A.W.; Basu, P. The Effect of Exchange Cations on Acidity, Activity, and Selectivity of Faujasite Cracking Catalysts. J. Catal. 1993, 143, 594-600.

32. Pron, A.; Kulszewicz, I.; Billaud, D.; Pryluski, J. Organic metals reaction of $\mathrm{FeCl}_{3}$ with Polyacetylene, $(\mathrm{CH})_{\mathrm{x}}$, and poly-(p-phenylene), $\left(\mathrm{p}-\mathrm{C}_{6} \mathrm{H}_{4}\right)_{\mathrm{x}}$. J. Chem. Soc. Chem. Commun. 1981, 15 , 783-784.

33. Chuapradit, C.; Wannatong, L.R.; Chotpattananont, D.; Sirivat, A.; Schwank, J. Polyaniline/ zeolite LTA composites and electrical conductivity. Polymer 2005, 46, 947-953.

34. Densakulprasert, N.; Wannatong, L.; Chotpattananont, D.; Hiamtup, P.; Sirivat, A.; Schwank, J. Electrical conductivity of polyaniline/zeolite composites and synergetic interaction with CO. Mat. Sci. Eng. B-Solid 2005, 117, 276-282.

35. Yamamoto, K.; Gu, H.B. Effect of Ammonium Gas on Electrical Property of Conductive Polymers. Jpn. J. Appl. Phys. 1986, 25, 1064-1068.

36. Kosacki, I.; Anderson, H.U. Nanostructured oxide thin films for gas sensors. Sens. Actuat. B-Chem. 1998, 48, 263-269. 
37. Shabnam, V.S.; Kaner, R.B.; Weiller, B.H. Hydrogen sensors based on conductivity changes in polyaniline nanofibers. J. Phys. Chem. B 2006, 110, 22266-22270.

38. Bredas, J.R. Theoritical studies of charged defect states in doped polyacetylene and polyparaphenylene. Mol. Cryst. Liq. Cryst. 1981, 77, 319-332.

39. Bradas, J.R. Comparative theoretical study of the doping of conjugated polymer: polarons in polyacetylene and polyparaphenylene. Phys. Rev. 1982, 26, 5843-5854.

40. Yin, F.; Blumenfeld, L.; Gruver, V.; Fripait, J.J. $\mathrm{NH}_{3}$ as a probe molecule for NMR and IR study of zeolite catalyst acidity. J. Phys. Chem. B 1997, 101, 1824-1830.

(C) 2009 by the authors; licensee Molecular Diversity Preservation International, Basel, Switzerland. This article is an open-access article distributed under the terms and conditions of the Creative Commons Attribution license (http://creativecommons.org/licenses/by/3.0/). 